\title{
INTERACT: A comprehensive approach to assess urban form interventions through natural experiments
}

Yan Kestens ${ }^{1 *}\left(\mathbb{D}\right.$, Meghan Winters ${ }^{2}$, Daniel Fuller ${ }^{3}$, Scott Bell ${ }^{4}$, Janelle Berscheid ${ }^{4}$, Ruben Brondeel $^{1}$, Michael Cantinotti ${ }^{5}$, Geetanjali Datta ${ }^{1}$, Lise Gauvin ${ }^{1}$, Margot Gough ${ }^{4}$, Karen Laberee ${ }^{2}$, Paul Lewis ${ }^{1}$, Sébastien Lord ${ }^{1}$, Hui ( Henry) Luan ${ }^{3}$, Heather McKay ${ }^{6}$, Catherine Morency ${ }^{7}$, Nazeem Muhajarine ${ }^{4}$, Trisalyn Nelson ${ }^{8}$, Callista Ottoni ${ }^{5}$, Zoe Poirier Stephens ${ }^{1}$, Caitlin Pugh², Gabrielle Rancourt ${ }^{1}$, Martin Shareck', Joanie Sims-Gould ${ }^{5}$, Meridith Sones ${ }^{2}$, Kevin Stanley ${ }^{4}$, Benoit Thierry ${ }^{1}$, Calvin Thigpen ${ }^{7}$ and Rania Wasfi ${ }^{1}$

\begin{abstract}
Background: Urban form interventions can result in positive and negative impacts on physical activity, social participation, and well-being, and inequities in these outcomes. Natural experiment studies can advance our understanding of causal effects and processes related to urban form interventions. The INTErventions, Research, and Action in Cities Team (INTERACT) is a pan-Canadian collaboration of interdisciplinary scientists, urban planners, and public health decision makers advancing research on the design of healthy and sustainable cities for all. Our objectives are to use natural experiment studies to deliver timely evidence about how urban form interventions influence health, and to develop methods and tools to facilitate such studies going forward.
\end{abstract}

Methods: INTERACT will evaluate natural experiments in four Canadian cities: the Arbutus Greenway in Vancouver, British Columbia; the All Ages and Abilities Cycling Network in Victoria, BC; a new Bus Rapid Transit system in Saskatoon, Saskatchewan; and components of the Sustainable Development Plan 2016-2020 in Montreal, Quebec, a plan that includes urban form changes initiated by the city and approximately 230 partnering organizations. We will recruit a cohort of between 300 and 3000 adult participants, age 18 or older, in each city and collect data at three time points. Participants will complete health and activity space surveys and provide sensor-based location and physical activity data. We will conduct qualitative interviews with a subsample of participants in each city. Our analysis methods will combine machine learning methods for detecting transportation mode use and physical activity, use temporal Geographic Information Systems to quantify changes to urban intervention exposure, and apply analytic methods for natural experiment studies including interrupted time series analysis.

Discussion: INTERACT aims to advance the evidence base on population health intervention research and address challenges related to big data, knowledge mobilization and engagement, ethics, and causality. We will collect $\sim 100 \mathrm{~TB}$ of sensor data from participants over 5 years. We will address these challenges using interdisciplinary partnerships, training of highly qualified personnel, and modern methodologies for using sensor-based data.

Keywords: Natural experiment, Urban form intervention, big data, public health, Physical activity, Social participation, Well-being, Equity, GPS, Accelerometer

\footnotetext{
* Correspondence: yan.kestens@umontreal.ca

'École de Santé Publique de l'Université de Montréal / Centre de recherche du CHUM, Pavillon S, Tour St-Antoine - 850 St-Denis - S03-280 -, Montreal, QC H2X OA9, Canada

Full list of author information is available at the end of the article
}

(c) The Author(s). 2019 Open Access This article is distributed under the terms of the Creative Commons Attribution 4.0 International License (http://creativecommons.org/licenses/by/4.0/), which permits unrestricted use, distribution, and reproduction in any medium, provided you give appropriate credit to the original author(s) and the source, provide a link to the Creative Commons license, and indicate if changes were made. The Creative Commons Public Domain Dedication waiver (http://creativecommons.org/publicdomain/zero/1.0/) applies to the data made available in this article, unless otherwise stated. 


\section{Background}

The design of urban form or the built environment has been associated with people's physical activity [1], social participation [2], and well-being [3]. The built environment also plays an important role in shaping social inequities based on differential access to resources and exposures to risk conditions [4]. Evidence about the potential impact of urban form changes is needed. In Canada, the federal government recently pledged \$125 B for infrastructure projects over the next 10 years. While such investments may translate into positive health benefits, primarily due to increases in physical activity [5], natural experiment studies on urban form changes to date have been scarce.

Physical inactivity is the fourth leading cause of death globally responsible for some $9 \%$ of premature mortality and $6-10 \%$ of coronary heart disease, diabetes, and breast and colon cancers [6]. If the population added just $10 \mathrm{~min}$ of physical activity per day substantial health benefits at the population level would be achieved [7, 8]. Interventions at the environment and policy levels are considered key to achieve such population-level changes [6]. Lack of social participation has, in turn, been linked to myocardial infarction, stroke, cancer, and diabetes [9-11], especially among older adults and vulnerable populations. Well-being is an essential resource for individual's health and is considered as a measure of societal progress [12]. The characteristics of the urban environments represent an interesting strategy to optimize the well-being of the population through changes in urban form [13-15].

Population and public health is committed to measuring and modifying urban form to support physical activity, social participation, and well-being, as well as reduce social inequities in health [16]. Urban form infrastructure [17], including cycling infrastructure [18] and traffic calming [19], is less likely to be implemented in low income areas, potentially exacerbating existing social inequities in health. Thus, stakeholders including urban planners, public health officials, and policy makers could benefit from more rigorous evidence to identify urban interventions that enhance population health and reduce social inequities in health $[20,21]$.

Natural experiment studies have been proposed as an important method to study how the large investments in infrastructure could cause health benefits related to physical activity, social participation, and well-being. Natural experiment studies are of interest because they can improve causal claims and lead to relevant and timely policy recommendations [22]. However, in a review of natural experiments evaluating policy and urban form changes on obesity-related outcomes, of the 17 studies that examined impacts on physical activity [23] only four had a strong study design (i.e., longitudinal studies with a comparison group), and most measured outcomes through self-reports or direct observation (e.g., cyclist counts), which have known limitations. Nonetheless, technological innovations related to mobile sensing can overcome some of the methodological limitations of natural experiment studies. These include the ability to reliably measure individual physical activity and daily mobility patterns using mobile sensors $[24,25]$.

Funded by the Canadian Institutes of Health Research, the INTErventions, Research, and Action in Cities Team (INTERACT) is a pan-Canadian collaboration of interdisciplinary scientists, urban planners, and public health decision makers advancing research on the design of healthy and sustainable cities for all. In partnership with cities and citizens, INTERACT is collecting big data to deliver timely public health evidence about influence of urban form interventions on health, well-being, social participation, and social inequities in these outcomes. Our objectives are to use natural experiment studies to deliver timely evidence about how urban form interventions influence health, and to develop methods and tools to facilitate such studies. Specifically, we will conduct natural experiment studies of urban form changes in four Canadian cities, with the aims to:

1. Understand Context: to characterize the context for changes in urban form, from an intersectoral perspective.

2. Measure Change: to refine measurement of changes in urban form exposures and outcomes using innovative methodological tools that integrate mobile sensing and Geographic Information Science.

3. Analyze Impact: to determine the impact of changes in urban form on physical activity, social participation, well-being, and related social inequities.

4. Mobilize Knowledge: to guide decision making on healthy urban planning and enhance training and capacity for urban form research in Canada using our evidence, methods, and tools.

\section{Conceptual framework}

The INTERACT conceptual framework (Fig. 1) is organized along four aims that emerged from a concept mapping activity among the research team and stakeholders, and reflect the intersectoral perspectives at play in urban form and health. Each aim includes a series of methodological tools that the INTERACT team will refine or develop (see grey box).

\section{Methods}

Interventions and cities

The INTERACT project will examine the potential health impacts of interventions in four Canadian cities.

Victoria (All Ages and Abilities (AAA) Cycling Network), a commitment of $\$ 14.3 \mathrm{M}$ to implement an All 


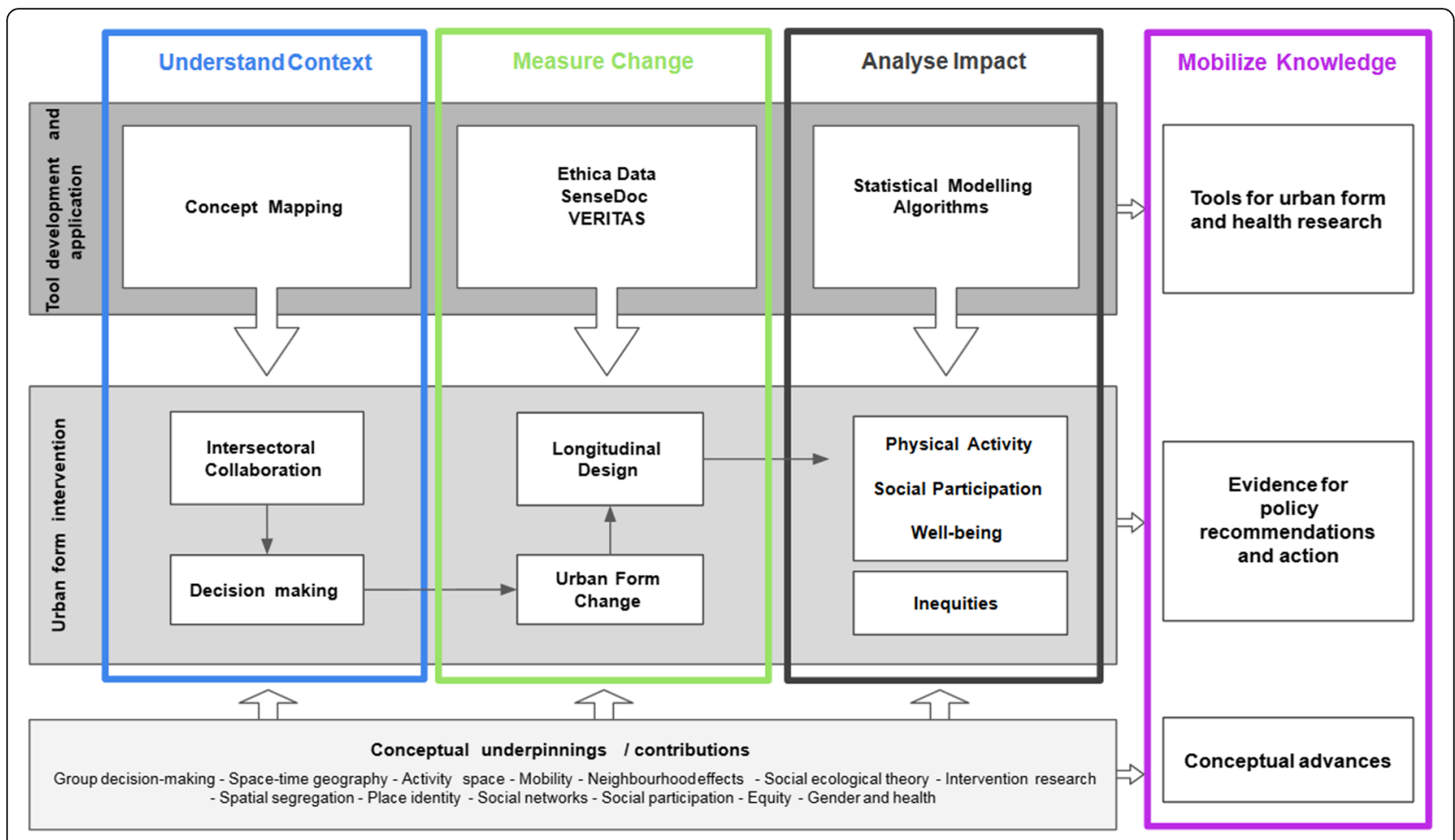

Fig. 1 Conceptual framework for the INTERACT studies

Ages and Abilities (AAA) Cycling Network, starting with the implementation of a $5.4 \mathrm{~km}$ grid in the downtown core. Protected bike lanes, off-street paths, and low-volume shared-use routes will connect every neighbourhood and regional trails [26].

Vancouver (Arbutus Greenway), a $9 \mathrm{~km}$ rail corridor the City of Vancouver purchased in 2016 for $\$ 55 \mathrm{M}$, which is being developed into a continuous walking and cycling corridor through prime real estate connecting South Vancouver to False Creek [27].

Saskatoon (Bus Rapid Transit (BRT)), a \$66 M investment in a $22 \mathrm{~km}$ Saskatoon BRT system along three major roadways. BRT is an enhanced bus system, operating on bus lanes or other transit ways to combine the flexibility of buses with the efficiency of rail [28].

Montreal (Sustainable Development Plan 2016-2020), reflects a total investment over $\$ 100 \mathrm{M}$, is a comprehensive sustainability plan which includes urban form changes initiated by the city and approximately 230 partnering organizations that will be implemented. We will specifically evaluate how traffic calming measures, changes in transportation infrastructure, place making, and greening program influence our outcomes of interest [29].

\section{Design}

\section{Governance and partnerships}

INTERACT is a pan-Canadian, bilingual team working collaboratively with local and national partners. The
INTERACT Charter sets out the purpose, guiding principles, and inner workings of our team. While there is no one-size-fits-all approach to governance, having a clear and agreed upon structure showing how groups, objectives, and functions fit together to achieve its mission is an important element of successful research teams [30]. INTERACT's governance structure includes six intersecting levels: management hub, executive committee, international advisory board, champions, expert teams, and intervention teams (Fig. 2). The intervention teams are intersectoral action-oriented teams guiding site-specific activities; the governance structure highlights that additional INTERACT sites may be added to the four existing study sites, given new funding or opportunities.

\section{Intervention context}

We will measure the intersectoral context of the interventions and their implementation using concept mapping. This method documents and synthesizes views and perceptions of groups and identifies convergent and divergent views between subgroups [31]. Concept mapping will be used to describe diverse stakeholders' perspectives on the factors that influence the success or failure of the INTER$\mathrm{ACT}$ urban form interventions prior to the interventions.

\section{Study design}

The INTERACT study design is a mixed methods prospective natural experiment study that will follow adult 

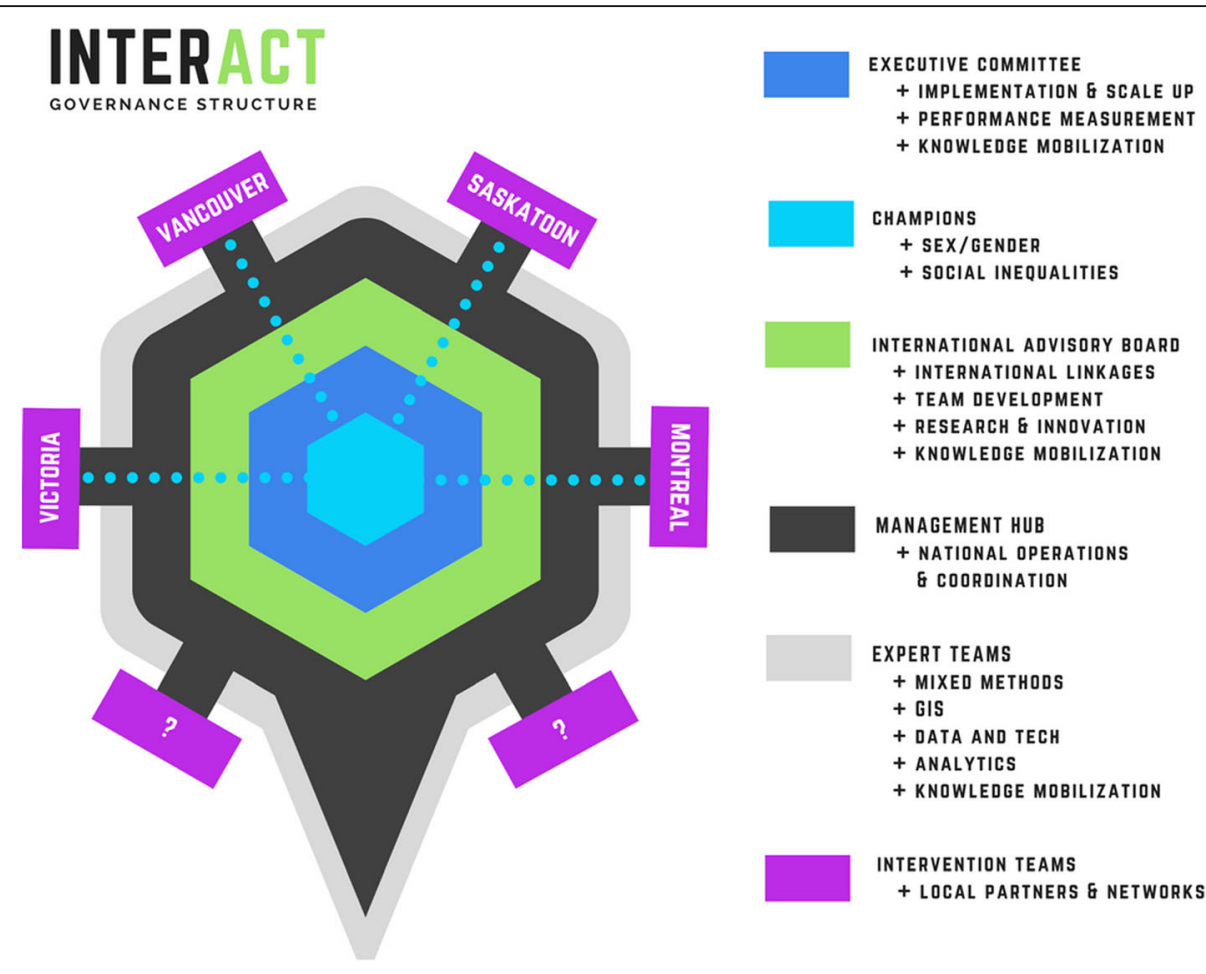

Fig. 2 INTERACT governance structure

participants (aged 18 and older) which will be implemented in each of four cities across five years. Our research approach collects comparable data between sites and also allows site-specific research activities. Quantitative data will be acquired over three data collection waves, baseline prior to or over the course of the intervention launch, and two follow-up time points. Timing of follow-up will be based on city context and each city's intervention timeline. Figure 3 represents typical data collection waves and intervention implementation.

We will use qualitative methods to explore participants' experience of urban form change as it pertains to physical activity, social participation, and well-being. These may include semi-structured individual interviews, or go-along methods, depending on the site. Detailed observation notes and videos of the interventions will be taken at each site.

\section{Sampling plan}

In Victoria, Vancouver, and Saskatoon we will aim to recruit 300 adult participants per site at baseline. We will use an open cohort methodology and recruit new participants to ensure a consistent sample size in follow-up waves. We will recruit samples representative of the age, gender, and socio-economic status specific to our exposure criteria in each city. In Montreal, where the exact location and timeline of interventions is not known a priori, meaning changes could be implemented anywhere throughout the city, 3000 adult participants will be recruited. Table 1 presents the inclusion criteria for

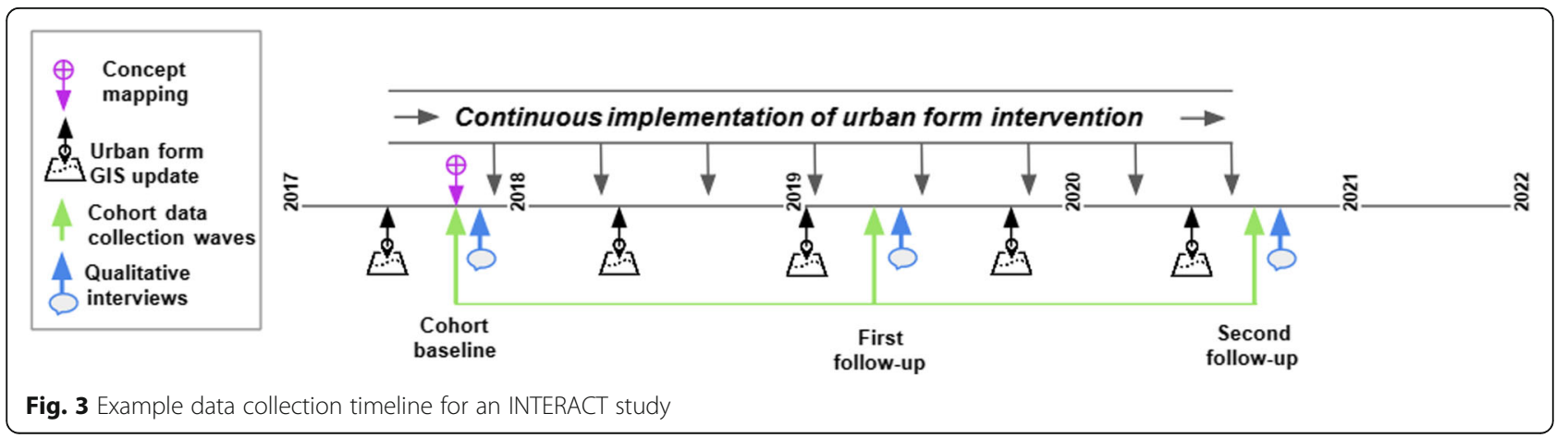


Table 1 Inclusion criteria for participants in the four INTERACT cities

\begin{tabular}{ll}
\hline City & Inclusion Criteria \\
\hline Victoria & - Living in the Capital Regional District \\
& - Bicycle at least once a month in the City of Victoria. \\
Vancouver & - Living within $3 \mathrm{~km}$ of the Arbutus Greenway \\
& - Leave home at least once a week \\
Saskatoon & Living in the City of Saskatoon \\
& - Take the bus in Saskatoon at least once per month \\
& or live within an $800 \mathrm{~m}$ buffer of the Bus Rapid \\
& Transit lines \\
Montreal & - Living in Montreal Metropolitan Area (Island of \\
& Montreal, Laval, Longueil, St-Lambert, Brossard) \\
& - Leave home at least once a week \\
\hline
\end{tabular}

each city, which varies based on the intervention being implemented in terms of target user and geographic scale. The exclusion criteria in all cities are being less than 18 years old, not being able to read or write English (or English or French in Montreal) well enough to answer an online survey and any intention to move out of the region in the next two years.

\section{Data collection}

We require at a minimum that participants complete an online survey, and in addition they may choose to install an app on their mobile device, wear a mobile sensing device, participate in qualitative interviews, or any combination of the above. For participants who may be interested in the study but do not have internet access and a computer we will provide the opportunity to complete the surveys in person or over the phone with a research assistant. Figure 4 shows the flow diagram for potential participants in the INTERACT studies. Ethics approval has been received from the ethics boards of Simon Fraser University, the University of Saskatchewan, the Centre de Recherche du Centre hospitalier de l'Université de Montréal, and Memorial University of Newfoundland.

\section{Quantitative data collection methods}

We will use online surveys and two mobile sensing methods to collect quantitative data. Online surveys will be used to measure health, physical activity, social participation, travel behaviour, well-being, and activity spaces. The surveys are posted on the team website. We will use the Visualisation, Evaluation and Recording of Itineraries and Activity Spaces (VERITAS), an online map-based survey that collects data to measure participant activity spaces and social networks [32].

The mobile sensing tools used to collect physical activity and spatial location data will be Ethica Data [33], an iOS and Android smartphone app, and SenseDoc [34] a research grade accelerometer device. Participants will be asked to install Ethica Data on their phone for 30 days and/or to wear a SenseDoc for 10 days. We will combine

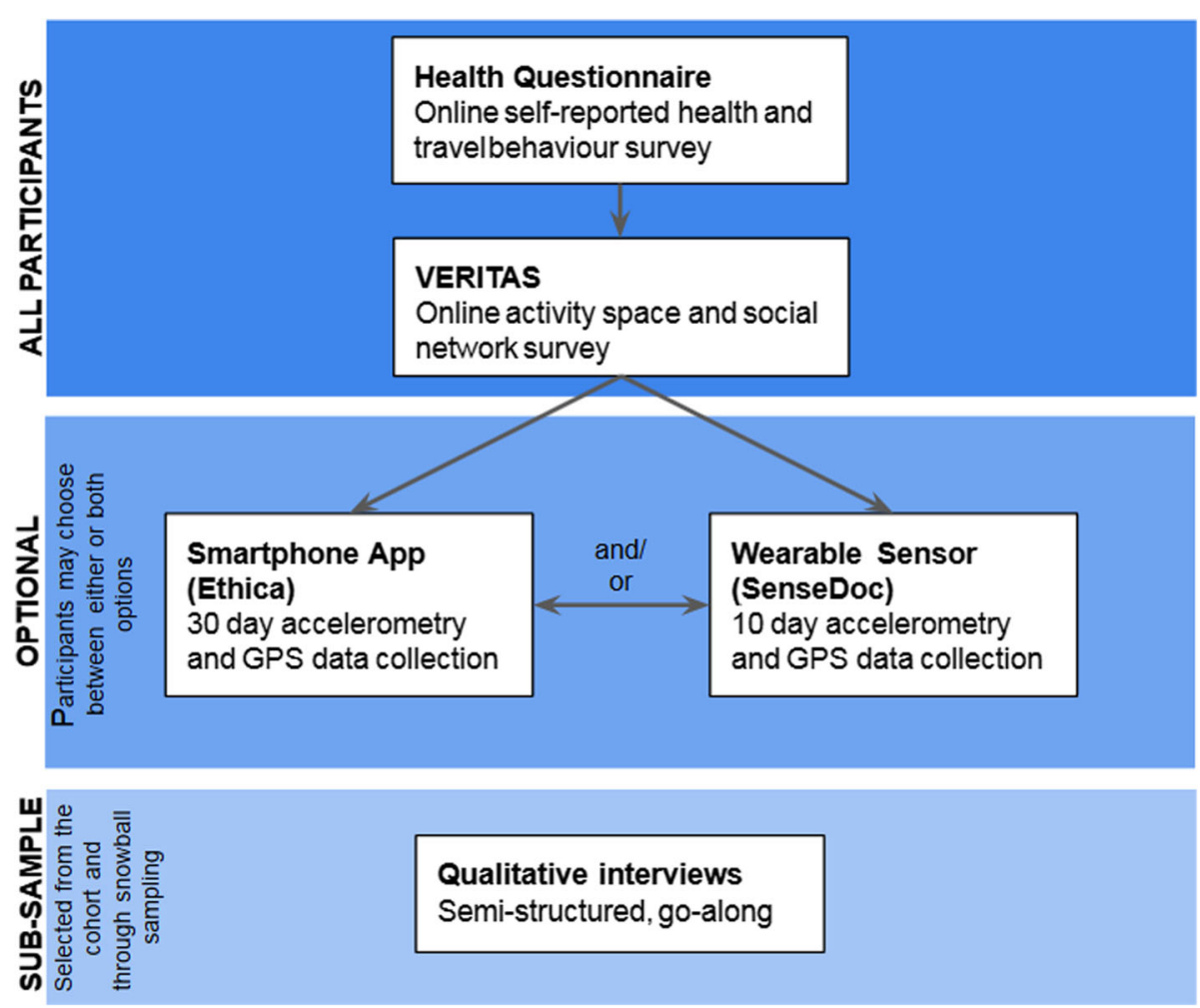

Fig. 4 Participant flow diagram for INTERACT studies 
accelerometer and Global Positioning System (GPS) data in order to measure location-based physical activity and infer transportation mode [35, 36].

We will use the Ethica Data smartphone app to measure well-being using ecological momentary assessment. We will use the validated Short Mood Scale [37], which measures three dimensions of affective states: valence, calmness, and energetic arousal.

\section{Qualitative data collection methods}

We will use qualitative approaches to explore participants' experience of urban form change as it pertains to physical activity, social participation, and well-being. We will recruit approximately 20 participants per site, by selecting participants from the cohort and supplementing with criterionsnowball sampling [38] and respondent-driven snowball sampling [39]. Our approach will consist of a semi-structured interview to gather descriptions of individual experiences of urban form, in general and with respect to the specific intervention. Qualitative data collection will also involve go-along interviews in certain cities [40].

\section{Exposure measurement}

Measuring exposure is crucial to correctly estimate the impact of interventions on our outcomes of interest [41]. Through partnerships with knowledge users we will use existing resources such as local city data, and open data to collect exposure data. Assigning individuals to exposed and unexposed groups in natural experiment studies is challenging, both from a conceptual and methodological standpoint [41]. As people move through urban environments, exposure is a dynamic rather than a static process. We will measure absolute and relative exposure to the urban form intervention using at least three methods: home location, activity space, and daily GPS path [42, 43]. Our approach will allow us to compare static and dynamic methods for measuring exposure and contribute to the discussion of how to define and measure exposure to urban form.

\section{Power}

Sample size calculations for natural experiment studies have little precedent [44]. Longitudinal and cross-sectional mobile sensing studies have used sample sizes ranging from 34 to 550 [58-62] and 28 to 1300 [63-70], respectively [45-51]. We used the EpiTools cohort study sample size calculator (http://epitools.ausvet.com.au/) with parameters based on the physical activity literature. Assuming repeated measures, power of 0.8 , alpha of 0.05 , expected incidence in the unexposed of 0.15 , and expected relative risk from 1.5 to 1.8 , we estimate that between 422 and 683 participants will be required to detect intervention effects. However, the implications for power with thousands of repeated measures per participant are still not well defined in the literature [52].

\section{Measures}

We have based our methodology on existing knowledge in order to develop the data analysis plan in as much detail as possible; however, the INTERACT project will require the adoption of new methodologies currently in development. As a team we are committed to open science and will post code and analyses online (https:// github.com/teaminteract).

\section{Physical activity}

We will assess physical activity both through self-report (questionnaire) and objective (Ethica smartphone app and SenseDoc devices) measures. With objective data, we will create measures of total volume of physical activity, cut-points for physical activity intensity levels, and activity type (e.g. sitting) [53]. To our knowledge, there has been limited development of cut-points of physical activity intensity using smartphones [54]. Studies using raw accelerometer data have employed a number of different machine learning methods including artificial neural networks to develop physical activity indicators from smartphone data $[55,56]$.

\section{Well-being}

We conceptualize well-being along hedonic and eudaimonic dimensions. Hedonic well-being focuses on the presence of positive affect, the absence of negative affect and the cognitive evaluation one's satisfaction with life. Eudaimonic well-being refers to optimal psychological functioning [57]. We will measure intra-daily variations in affective components of hedonic well-being via Ecological Momentary Assessment (EMA) using the Short Mood Scale [58]. INTERACT will measure cognitive components of hedonic well-being via the health survey using the Subjective Happiness Survey [59] and the eudaimonic well-being using the Personal Well-Being Index (PWI-A) [60]. More in-depth feelings of both dimensions of well-being will be explored with the qualitative research component.

\section{Social participation}

We will measure social participation using the Sense of Community Belonging questions from the Canadian Community Health Survey [58], the Social Cohesion and Trust question (Collective Efficacy) from the Project on Human Development in Chicago Neighborhoods study [61], and the question on trust and reciprocity from the General Social Survey [62]. The map-based VERITAS survey will further allow us to measure participants' social network size and strength. Finally, deeper experiences 
with social participation related to urban form will be explored within the semi-structured interviews.

\section{Transportation mode detection}

To examine changes in transportation based physical activity, we will need to develop or apply existing methods that will allow us to predict transportation mode and activity locations. There is considerable research currently being produced in this area $[63,64]$. We will apply those methods that provide sufficient accuracy for our needs, but will develop or modify new analytic techniques for trip mode detection when necessary.

\section{Geographic Information system (GIS) exposure}

Measuring and understanding exposure to and changes in the urban environment is crucial for our work. Our team has also reviewed GIS measures in the literature to characterize green space, park access, land use mix, transit access, and bike infrastructure, in order to identify optimal measures for our project. There are currently a number of methods being developed with potential application to our work [64-66]. For instance, our team members have used network kernel density estimation to examine changes in cycling collisions [67]. This method could be generalized to different types of spatial data (ie. polygon and polyline) that will be necessary to understand changes in exposure over time.

\section{Data analysis \\ Intervention analysis}

The potential for natural experiment studies to improve causal claims about intervention effects has received considerable attention $[68,69]$. There are a number of potential analysis methods including, regression discontinuity [70], difference in differences [71] and interrupted time series [72] that will be adopted to examine the impact of the natural experiments. As INTERACT data collection is longitudinal within each intervention city, our planned method for impact assessment will be interrupted time series. Analyses applying regression discontinuity and difference in differences are also possible depending on the research question. Analysis methods for causal inference are advancing quickly [73] and we will implement new methods that are relevant and applicable to INTERACT research questions.

\section{Qualitative analysis}

Interview recordings will be transcribed verbatim by a professional transcription agency. Data will be analyzed using framework analysis [74], an appropriate analytic approach for qualitative studies with specific questions, a pre-designed sample, and issues identified a priori. We will create a broad coding framework aligned with the aim of each interview question. During a second cycle of coding, we will apply a focused coding procedure to the broad coding framework. In a third and final cycle, we will simplify the coding framework into thematic categories, and reach consensus on this final codebook. The study team will meet regularly during data collection to discuss coding and the preliminary findings, as a step to ensure rigour.

\section{Equity analysis}

We will examine how intervention impacts are socially and spatially patterned using an equity analysis approach [75]. This approach focuses on factors that impact the spatial distribution of exposure, the spatial distribution of populations, population vulnerability, and the interaction between these factors.

\section{Discussion}

INTERACT is a pan-Canadian collaboration of interdisciplinary scientists, urban planners, and public health decision makers advancing research on the design of healthy and sustainable cities for all. Seeing the city as a living laboratory, we are using innovative tools such as mobile technology to measure the impact of changes in urban infrastructure on people's physical activity, social participation, and well-being, and inequities in these outcomes. With INTERACT's aim to advance the evidence base and generate new tools, the project will face diverse challenges. We highlight considerations related to big data, knowledge mobilization and engagement, ethics, and causality below.

\section{Big data}

We estimate that INTERACT will collect approximately 100 terabyte (TB) of raw data during the study period. The volume and variety of data make data security, storage, and processing a crucial consideration for the INTERACT study. We plan on partnering with both the Centre for Health Information and Analytics at Memorial University and Compute Canada for data infrastructure requirements. There are considerable training requirements for public health researchers and students in both data handling and machine learning methods [25]. We will develop training modules related to working with large data infrastructure, programming in Python and R, and methods for analyzing large spatio-temporal datasets.

\section{Knowledge mobilization}

The INTERACT program is guided by a framework for sustained impact [76], which highlights the importance of early and sustained engagement with non-government organizations and policy makers nationally and locally. The meaningful engagement of intersectoral stakeholders throughout the research process will be guided by a governance model that prioritizes consultation and collective 
decision-making, and the equitable participation of knowledge users. For example, city decision-makers are integrated within intervention teams, positioning them to provide input on local research questions and methods, and to facilitate evidence-informed decision-making. We have a diversity of knowledge translation end products planned, including both applied and scholarly outputs relevant to municipalities, regional governments, health authorities, non-governmental organizations, academics, and citizens. One example is that we have adopted a process of rapid reviews that can inform research or policy at the local level. We also aim to enhance training and capacity for urban form research through open and wide dissemination of INTERACT's evidence, tools, and methods to both practitioner and research communities.

\section{Ethics}

There are ethical considerations for INTERACT, specifically related to the high precision location data collected from participants [77]. In natural experiment studies using mobile sensing it is important to recognize risks that are part of the intervention, and risks that arise through unintended circumstances during the study. Risks related to the intervention are unlikely in a natural experiment study because researchers do not control the intervention [77]. There are risks related to using mobile sensing data for health research including consent, privacy and confidentiality, mitigating risk, and vulnerable populations. We will mitigate potential risks by using plain language consent forms, having clear Frequently Asked Questions (FAQ) support for participants, updating participants about the data they are contributing, using secure protocols for data storage and access, and training research trainees and staff on data security and access $[78,79]$.

\section{Causality}

Making causal claims about intervention effects is the primary objective of epidemiologic studies [80]. Regression discontinuity, difference in differences, and interrupted-times series are methods that can permit causal claims to be made about intervention effects in observational research, provided that the assumptions of the methods are met. A challenge of evaluating the impact of urban form interventions is that interventions and individual level exposures are changing in both time and space [81]. In contrast to strict interventions, which can be implemented from one day to the next, urban form interventions are implemented over longer time periods and often in phases. The nature of urban form interventions will require us to test multiple methods for defining exposure both temporally and spatially, and cautiously interpret our results. The on-going nature of the intervention implementation and confounding by other urban form changes will be a challenge for causal attribution [82].

\section{Limitations}

INTERACT faces limitations related to sampling bias, control groups, intervention specificity, and context. Sampling bias may take two forms. First, vulnerable populations are less likely to participate in research in general and may be even less likely to participate in research involving mobile sensing, either because they may not have these devices or because the detailed location data collection may be considered additionally intrusive to these populations [78]. Second, we have not a priori identified control groups, either in the form of comparable cities or comparable unexposed groups, for our interventions. However, for some research questions, spatial exposure can serve to identify levels of exposure within the sample. Third, INTERACT will evaluate four different urban form interventions in four different cities. Both the conceptual and statistical identification of the hypothesized and actual intervention effects and which aspects of the intervention we are evaluating is challenging. There are several potentially relevant contextual features to consider including: inequities, public consultations, media campaigns, and political decision making. With only four cities included, we are using an ad hoc approach to consider how these and other contextual factors should be considered in our analysis.

INTERACT will harness big data to deliver timely public health evidence on the influence of real-world urban form interventions on physical activity, well-being, and social participation, as well as social inequities in these outcomes. We aim to understand context, measure change, analyze impact, and mobilize knowledge about how the urban form can influence health.

\section{Abbreviations \\ AAA: All Ages and Abilities; BRT: Bus Rapid Transit; EMA: Ecological Momentary Assessment; FAQ: Frequently Asked Questions; GIS: Geographic Information System; GPS: Global Positioning System; \\ INTERACT: INTErventions, Research, and Action in Cities Team; PWI- A: Personal Well-Being Index-Adult; TB: Terabyte; VERITAS: Visualisation, Evaluation and Recording of Itineraries and Activity Spaces}

\section{Acknowledgements}

We would like to acknowledge our local and national research partners: Coralie Deny, Conseil régional de l'environnement de Montréal. Louis Drouin, Direction régionale de santé publique - CIUSS du Centre-Sud-de-l'̂lle-de-Montréal. Danielle Lussier, Ville de Montréal. Raphaël Massé, Table de concertation des aînés de lîle de Montréal. Richard Massé, Direction régionale de santé publique - CIUSS du Centre-Sud-de-I'Tle-de-Montréal. Sophie Paquin, Direction régionale de santé publique - CIUSS du Centre-Sud-de-l'île-de-Montréal. Maëlle Plouganou, Table de concertation des aînés de l'̂le de Montréal. Lesley Anderson, City of Saskatoon. James McDonald, City of Saskatoon. Rob Dudiak, City of Saskatoon. Chris Schulz, City of Saskatoon. Cory Shrigley, City of Saskatoon. Allison Gray, City of Saskatoon. Dale Bracewell, City of Vancouver. Keltie Craig, City of Vancouver. Claire Gram, Vancouver Coastal Health. Sarah Webb, City of Victoria. John Hicks, Capital Regional District. Kate Berniaz, Capital Regional District. Daniel Bolduc, Institut national de santé publique du Québec. Glenn Miller, Canadian Urban Institute. Éric Robitaille, Institut 
national de santé publique du Québec. Olivier Bellefleur, National Collaborating Centre for Healthy Public Policy.

\section{Funding}

INTERACT is funded under the Team Grant: Environments and Health: Intersectoral Prevention Research / Subvention d'équipe: Santé et environnements: Recherche intersectorielle en prevention. July 13, 2016 Competition Code: 201607IP5. The funding reference number IP2-1507071C.

\section{Availability of data and materials}

The datasets generated and/or analyzed during the current study are not publicly available because they contain highly detailed individual location data about participants, but are available from the corresponding author on request. Sharing of location data will also require ethics approval from the requesting author's institution.

\section{Authors' contributions}

$Y K, M W$, and DF equally contributed to the conceptualization of the study. $\mathrm{SB}, \mathrm{JB}, \mathrm{RB}, \mathrm{MC}, \mathrm{GD}, \mathrm{LG}, \mathrm{MG}, \mathrm{KL}, \mathrm{PL}, \mathrm{SL}, \mathrm{HL}, \mathrm{HM}, \mathrm{CM}, \mathrm{NM}$, TN, CO, ZPS, CP, GR $M S, J S G, M S, K S, B T, C T$, and RW contributed to manuscript preparation and approved the final version. All authors read and approved the final manuscript

\section{Ethics approval and consent to participate}

Ethical approval has been received from the ethics boards of Simon Fraser University (2017 s0158, 2017 s0531, and 2018 s0127), the University of Saskatchewan (17-347), the Centre de Recherche du Centre hospitalier de I'Université de Montréal (CÉR CHUM 16.397), and Memorial University of Newfoundland (20180446). All participants will provide consent via online or a hard copy form

\section{Consent for publication}

Not Applicable.

\section{Competing interests}

Yan Kestens (NPI) and Benoit Thierry hold shares in Mobysens Technologies Inc., a spin-off company that markets the SenseDoc 2.0. The SenseDoc is a multisensor device used for mobility (GPS) and physical activity (accelerometer) tracking in the INTERACT study. The SenseDoc was filed as an invention in 2013 at Univalor (www.univalor.ca), the valorisation company affiliated with Université de Montréal and Centre de Recherche du CHUM. Yan Kestens (NPI) holds shares in Treksoft Solutions Inc., a spin-off company that markets an online survey platform. It hosts the VERITAS application (map-based survey tool) and eKogito (concept mapping application), two tools that will be used in the INTERACT project. VERITAS was filed as an invention in 2012 at Univalor, the valorisation company affiliated with Université de Montréal. eKogito was filed as an invention at Aligo (www.aligo.ca) in 2013, through Université du Québec à Trois-Rivières.

Kevin Stanley (Co-I) holds shares in EthicaData Inc., a company marketing the Ethica Health smartphone app that will be used to collect data on mobility and physical activity through participants' smartphones.

Michael Cantinotti (Co-l) participated in the development of the eKogito application within his university, which has licensed the software through his technology transfer company. The author has no financial involvement with the third-party company that distributes the application.

Daniel Fuller (PI) is an associate editor with BMC Public Health.

\section{Publisher's Note}

Springer Nature remains neutral with regard to jurisdictional claims in published maps and institutional affiliations.

\section{Author details}

'École de Santé Publique de l'Université de Montréal / Centre de recherche du CHUM, Pavillon S, Tour St-Antoine - 850 St-Denis - S03-280 -, Montreal, QC H2X 0A9, Canada. 'Simon Fraser University, 8888 University Drive, Burnaby, BC V5A 1S6, Canada. ${ }^{3}$ Memorial University of Newfoundland, 230 Elizabeth Avenue, St. John's, NF A1C 5S7, Canada. ${ }^{4}$ University of Saskatchewan, 105 Administration Place, Saskatoon, SK S7N 5A2, Canada. ${ }^{5}$ Université du Québec à Trois-Rivières, 3351 Boulevard des Forges, Trois-Rivières, QC G9A 5H7, Canada. ${ }^{6}$ University of British Columbia, 2329 West Mall, Vancouver, BC V6T 1Z4, Canada. ${ }^{7}$ Polytechnique Montréal, 2900 Edouard Montpetit Blvd, Montreal, QC H3T 1J4, Canada. ${ }^{8}$ Arizona State
University, PO Box 875302, Tempe, AZ 85287-5302, USA. ${ }^{9}$ University of Toronto, 155 College Street, Toronto, ON M5T 1P8, Canada.

Received: 13 July 2018 Accepted: 18 December 2018

Published online: 10 January 2019

\section{References}

1. Ding D, Gebel K. Built environment, physical activity, and obesity: what have we learned from reviewing the literature? Heal Place [Internet]. 2012;18(1): 100-5. Available from: http://www.ncbi.nlm.nih.gov/pubmed/21983062.

2. Leyden KM. Social capital and the built environment: the importance of walkable neighborhoods. Am J Public Health [Internet]. 2003 [cited 2018 Apr 24];93(9):1546-51. Available from: http://www.ncbi.n/m.nih.gov/ pubmed/12948978.

3. Halpern D. Mental health and the built environment : more than bricks and mortar? Routledge; 2014. p. 240.

4. McCormack GR, Shiell A, Doyle-Baker PK, Friedenreich CM, Sandalack BA Subpopulation differences in the association between neighborhood urban form and neighborhood-based physical activity. Health Place [Internet]. 2014 [cited 2018 Apr 25];28:109-15. Available from: http://www.ncbi.n/m.nih gov/pubmed/24797923.

5. Woodcock J, Edwards P, Tonne C, Armstrong BG, Ashiru O, Banister D, et al. Public health benefits of strategies to reduce greenhouse-gas emissions: urban land transport. Lancet (London, England) [Internet]. 2009 Dec 5 [cited 2018 Apr 25];374(9705):1930-43. Available from: http://www.ncbi.nlm.nih. gov/pubmed/19942277.

6. Kohl HW, Craig CL, Lambert EV, Inoue S, Alkandari JR, Leetongin G, et al. The pandemic of physical inactivity: global action for public health. Lancet (London, England) [Internet]. 2012 Jul 21 [cited 2018 Apr 25];380(9838):294305. Available from: http://www.ncbi.nlm.nih.gov/pubmed/22818941.

7. Woodcock J, Franco OH, Orsini N, Roberts I. Non-vigorous physical activity and all-cause mortality: systematic review and meta-analysis of cohort studies. Int J Epidemiol [Internet]. 2011 Feb 1 [cited 2018 Apr 25]:40(1):12138. Available from: http://www.ncbi.nlm.nih.gov/pubmed/20630992.

8. Wen CP, Wai JPM, Tsai MK, Yang YC, Cheng TYD, Lee M-C, et al. Minimum amount of physical activity for reduced mortality and extended life expectancy: a prospective cohort study. Lancet [Internet]. 2011 Oct 1 [cited 2018 Apr 25];378(9798):1244-53. Available from: http://www.ncbi.nlm.nih. gov/pubmed/21846575

9. Tomaka J, Thompson S, Palacios R. The Relation of Social Isolation, Loneliness, and Social Support to Disease Outcomes Among the Elderly. J Aging Health [Internet]. 2006 Jun 30 [cited 2018 Apr 25];18(3):359-84. Available from: http://www.ncbi.nlm.nih.gov/pubmed/16648391.

10. Cacioppo JT, Hawkley LC. Social isolation and health, with an emphasis on underlying mechanisms. Perspect Biol Med [Internet]. 2003 [cited 2018 Apr 25];46(3 Suppl):S39-52. Available from: http://www.ncbi.n/m.nih.gov/ pubmed/14563073.

11. Foley L, Prins R, Crawford F, Humphreys D, Mitchell R, Sahlqvist S, et al. Effects of living near an urban motorway on the wellbeing of local residents in deprived areas: Natural experimental study. PLoS One [Internet]. 2017 [cited 2018 Apr 25];12(4):e0174882. Available from: http://www.ncbi.nlm.nih. gov/pubmed/28379993.

12. OECD Guidelines on Measuring Subjective Well-being [Internet]. OECD Publishing; 2013 [cited 2018 Apr 25]. Available from: http://www.oecdilibrary.org/economics/oecd-guidelines-on-measuring-subjective-well-being 9789264191655-en

13. Nimegeer A, Thomson H, Foley L, Hilton S, Crawford F, Ogilvie D, et al. Experiences of connectivity and severance in the wake of a new motorway: Implications for health and well-being. Soc Sci Med [Internet]. 2018 [cited 2018 mar 26];197:78-86. Available from: http://www.ncbi.nlm.nih.gov/ pubmed/29222998.

14. McCay L, Bremer I, Endale T, Jannati M, Yi J. Urban Design and Mental Health. In Springer, Singapore; 2017 [cited 2018 Apr 25]. p. 1-24. Available from: http://link.springer.com/10.1007/978-981-10-0752-1 12-1

15. Evans GW. The built environment and mental health. J Urban Health [Internet]. 2003 Dec [cited 2018 Apr 25];80(4):536-55. Available from: http:// www.ncbi.nlm.nih.gov/pubmed/14709704

16. Public Health Agency of Canada. Designing Healthy Living [Internet]. [cited 2018 Jun 27]. Available from: https://www.canada.ca/en/public-health/ services/publications/chief-public-health-officer-reports-state-public-healthcanada/2017-designing-healthy-living.html 
17. Alphonsus KB, Waldner C, Fuller D. Examining the association between area level deprivation and vehicle collisions that result in injury. Can J Public Heal [Internet]. 2018;109(1):43-51 Available from: http://link.springer.com/10. 17269/s41997-018-0036-7.

18. Fuller D, Winters M. Income inequalities in bike score and bicycling to work in Canada. J Transp Heal [Internet]. 2017 Dec;7:264-8 Available from: https:// linkinghub.elsevier.com/retrieve/pii/S2214140517301573.

19. Morency P, Gauvin L, Plante C, Fournier M, Morency C. Neighborhood social inequalities in road traffic injuries: the influence of traffic volume and road design Am J Public Health [Internet]. 20129 [cited 2018 May 18];102(6):1112-9. Available from: http://ajph.aphapublications.org/doi/10.2105/AJPH.2011.300528

20. Petticrew M, Cummins S, Ferrell C, Findlay A, Higgins C, Hoy C, et al. Natural experiments: an underused tool for public health? Public Health [Internet]. 2005 [cited 2018 Apr 25];119(9):751-7. Available from: http://www.ncbi.nlm. nih.gov/pubmed/15913681.

21. Althoff T, Sosič R, Hicks JL, King AC, Delp SL, Leskovec J. Large-scale physical activity data reveal worldwide activity inequality. Nature [Internet]. 201710 [cited 2018 Apr 4];547(7663):336-9. Available from: http://www.nature.com/ doifinder/10.1038/nature23018

22. Leatherdale ST. Natural experiment methodology for research: a review of how different methods can support real-world research. Int J Soc Res Methodol [Internet]. 2018 Jul 2 [cited 2018 Oct 18];1-17. Available from: https://www.tandfonline.com/doi/full/10.1080/13645579.2018.1488449

23. Mayne SL, Auchincloss AH, Michael YL. Impact of policy and built environment changes on obesity-related outcomes: a systematic review of naturally occurring experiments. Obes Rev [Internet]. 2015 May [cited 2018 Apr 25];16(5):362-75. Available from: http://www.ncbi.nlm.nih.gov/pubmed/ 25753170.

24. Shen L, Stopher PR. Review of GPS Travel Survey and GPS Data-Processing Methods. Transp Rev [Internet]. 2014 [cited 2018 Apr 25];0. Available from: http://www.tandfonline.com/action/journallnformation?journalCode=ttrv20

25. Fuller D, Buote R, Stanley K. A glossary for big data in population and public health: discussion and commentary on terminology and research methods. J Epidemiol Community Health [Internet]. 2017 Nov 1 [cited 2018 Apr 25]; 71(11):1113-7. Available from: http://www.ncbi.nlm.nih.gov/pubmed/ 28918390.

26. Cycling | Victoria [Internet]. [cited 2018 Jun 19]. Available from: http://www. victoria.ca/EN/main/residents/transportation/cycling.html

27. Arbutus Greenway [Internet]. [cited 2018 Jun 19]. Available from: http:// vancouver.ca/streets-transportation/arbutus-greenway.aspx

28. Transit Plan | Saskatoon.ca [Internet]. [cited 2018 Jun 19]. Available from: https://www.saskatoon.ca/business-development/planning/plan-growth/ transit-plan

29. Ville de Montréal - Sustainable development - Sustainable Montréal 20162020 [Internet]. [cited 2018 Jun 19]. Available from: https://ville.montreal.qc. $\mathrm{ca} /$ portal/page?_pageid=7137,78111572\&_dad=portal\&_schema=PORTAL

30. Stewart M, Fortin M, Bouhali T, Denomme LB. Success in leading collaborative research. Can Fam Physician [Internet]. 2015 Jun [cited 2018 Jun 19];61(6):5656. Available from: http://www.ncbi.n/m.nih.gov/pubmed/26071160.

31. Novak JD. Concept mapping: A useful tool for science education. J Res Sci Teach [Internet]. 1990 Dec 1 [cited 2018 Apr 25];27(10):937-49. Available from: http://doi.wiley.com/10.1002/tea.3660271003

32. Chaix B, Kestens Y, Perchoux C, Karusisi N, Merlo J, Labadi K. An Interactive Mapping Tool to Assess Individual Mobility Patterns in Neighborhood Studies. Am J Prev Med [Internet]. 2012 Oct [cited 2018 Apr 25];43(4):44050. Available from: http://www.ncbi.nlm.nih.gov/pubmed/22992364.

33. Ethica Data [Internet]. [cited 2018 May 10]. Available from: https://www. ethicadata.ca/

34. Mobysens [Internet]. [cited 2018 May 10]. Available from: http://mobysens. com/en/

35. Thierry $B$, Chaix B, Kestens $Y$. Detecting activity locations from raw GPS data: a novel kernel-based algorithm. Int J Health Geogr [Internet]. 201316 [cited 2018 Apr 30];12(1):14. Available from: http://ij-healthgeographics. biomedcentral.com/articles/10.1186/1476-072X-12-14

36. Brondeel R, Pannier B, Chaix B. Using GPS, GIS, and Accelerometer Data to Predict Transportation Modes. Med Sci Sports Exerc [Internet]. 2015 Dec [cited 2018 Apr 30];47(12):2669-75. Available from: http://www.ncbi.nlm.nih. gov/pubmed/25984892.

37. Wilhelm P, Schoebi D. Assessing Mood in Daily Life. Eur J Psychol Assess [Internet]. 2007 Jan [cited 2018 Mar 12];23(4):258-67. Available from: http:// econtent.hogrefe.com/doi/abs/10.1027/1015-5759.23.4.258
38. Given LM. Purposive Sampling. In: Given LM, editor. The SAGE Encyclopedia of Qualitative Research Methods [Internet]. 2nd Editio. Thousand Oaks: Sage Publications, Inc.; 2008 [cited 2018 Apr 26]. p. 697-8. Available from: http:// www.yanchukvladimir.com/docs/Library/Sage\%20Encyclopedia\%20of\%20 Qualitative\%20Research\%20Methods-\%202008.pdf.

39. Lavrakas P. Encyclopedia of Survey Research Methods [Internet]. 2455 Teller Road, Thousand Oaks California 91320 United States of America : Sage Publications, Inc.; 2008 [cited 2018 Apr 26]. Available from: http://methods. sagepub.com/reference/encyclopedia-of-survey-research-methods

40. Tong C, Sims-Gould J, McKay H. InterACTIVE Interpreted Interviews (I3): A multi-lingual, mobile method to examine the neighbourhood environment with older adults. Soc Sci Med [Internet]. 2016 Nov 1 [cited 2018 Jun 19]; 168:207-13. Available from: https://www.sciencedirect.com/science/article/ pii/S0277953616304324

41. Humphreys DK, Panter J, Sahlqvist S, Goodman A, Ogilvie D. Changing the environment to improve population health: a framework for considering exposure in natural experimental studies. J Epidemiol Community Health [Internet]. 2016 Sep [cited 2018 Apr 26];70(9):941-6. Available from: http:// www.ncbi.nlm.nih.gov/pubmed/27056683.

42. Chaix B, Méline J, Duncan S, Merrien C, Karusisi N, Perchoux C, et al. GPS tracking in neighborhood and health studies: A step forward for environmental exposure assessment, a step backward for causal inference? Health Place [Internet]. 2013 May [cited 2018 Apr 26];21:46-51. Available from: http://www.ncbi.n/m.nih.gov/pubmed/23425661.

43. Hirsch JA, Winters M, Clarke P, McKay H. Generating GPS activity spaces that shed light upon the mobility habits of older adults: a descriptive analysis. Int J Health Geogr [Internet]. 2014 Dec 12 [cited 2018 Apr 26];13(1):51. Available from: http://ij-healthgeographics.biomedcentral.com/articles/10. 1186/1476-072X-13-51

44. Noordzij M, Tripepi G, Dekker FW, Zoccali C, Tanck MW, Jager KJ. Sample size calculations: basic principles and common pitfalls. Nephrol Dial Transplant [Internet]. 2010 May 1 [cited 2018 Apr 26];25(5):1388-93. Available from: http://www.ncbi.nlm.nih.gov/pubmed/20067907.

45. Yin L, Raja S, Li X, Lai Y, Epstein L, Roemmich J. Neighbourhood for Playing: Using GPS, GIS and Accelerometry to Delineate Areas within which Youth are Physically Active. Urban Stud [Internet]. 2013 Nov 16 [cited 2018 Apr 26];50(14):2922-39. Available from: http://journals.sagepub.com/doi/10.1177/ 0042098013482510

46. Wheeler BW, Cooper AR, Page AS, Jago R. Greenspace and children's physical activity: A GPS/GIS analysis of the PEACH project. Prev Med (Baltim) [Internet]. 2010 Aug [cited 2018 Apr 26];51(2):148-52. Available from: http:// www.ncbi.nlm.nih.gov/pubmed/20542493.

47. Carlson JA, Saelens BE, Kerr J, Schipperijn J, Conway TL, Frank LD, et al. Association between neighborhood walkability and GPS-measured walking, bicycling and vehicle time in adolescents. Health Place [Internet]. 2015 Mar [cited 2018 Apr 26];32:1-7. Available from: http://www.ncbi.nlm.nih.gov/ pubmed/25588788.

48. Klinker CD, Schipperijn J, Christian H, Kerr J, Ersbøll AK, Troelsen J. Using accelerometers and global positioning system devices to assess gender and age differences in children's school, transport, leisure and home based physical activity. Int J Behav Nutr Phys Act [Internet]. 2014 Jan 24 [cited 2018 Apr 26];11(1):8. Available from: http://ijbnpa.biomedcentral.com/ articles/10.1186/1479-5868-11-8

49. Almanza $E$, Jerrett $M$, Dunton $G$, Seto $E$, Ann Pentz M. A study of community design, greenness, and physical activity in children using satellite, GPS and accelerometer data. Health Place [Internet]. 2012 Jan [cited 2018 Apr 26];18(1):46-54. Available from: http://www.ncbi.nlm.nih. gov/pubmed/22243906.

50. Quigg R, Gray A, Reeder Al, Holt A, Waters DL. Using accelerometers and GPS units to identify the proportion of daily physical activity located in parks with playgrounds in New Zealand children. Prev Med (Baltim) [Internet]. 2010 May [cited 2018 Apr 26];50(5-6):235-40. Available from: http://www.ncbi.nlm.nih.gov/pubmed/20153361.

51. Gell NM, Rosenberg DE, Carlson J, Kerr J, Belza B. Built environment attributes related to GPS measured active trips in mid-life and older adults with mobility disabilities. Disabil Health J [Internet]. 2015 Apr [cited 2018 Apr 26];8(2):290-5. Available from: http://www.ncbi.nlm.nih.gov/pubmed/25637503.

52. Stieb DM, Boot CR, Turner MC. Promise and pitfalls in the application of big data to occupational and environmental health. BMC Public Health [Internet]. 2017 Dec 9 [cited 2018 Jun 19];17(1):372. Available from: https:// bmcpublichealth.biomedcentral.com/articles/10.1186/s12889-017-4286-8 
53. Bort-Roig J, Gilson ND, Puig-Ribera A, Contreras RS, Trost SG. Measuring and Influencing Physical Activity with Smartphone Technology: A Systematic Review. Sport Med [Internet]. 2014 May 5 [cited 2018 Apr 30];44(5):671-86. Available from: http://link.springer.com/10.1007/s40279-014-0142-5

54. Guidoux R, Duclos M, Fleury G, Lacomme P, Lamaudière N, Saboul D, et al. The eMouveRecherche application competes with research devices to evaluate energy expenditure, physical activity and still time in free-living conditions. J Biomed Inform [Internet]. 2017 May 1 [cited 2018 Apr 30]:69: 128-34. Available from: https://www.sciencedirect.com/science/article/pii/ S1532046417300758?via\%3Dihub

55. Staudenmayer J, Pober D, Crouter S, Bassett D, Freedson P. An artificia neural network to estimate physical activity energy expenditure and identify physical activity type from an accelerometer. J Appl Physiol [Internet]. 2009 Oct [cited 2018 Apr 26];107(4):1300-7. Available from: http://www.ncbi.nlm. nih.gov/pubmed/19644028.

56. Pober DM, Staudenmayer J, Raphael C, Freedson PS. Development of novel techniques to classify physical activity mode using accelerometers. Med Sci Sports Exerc [Internet]. 2006 Sep 1 [cited 2018 Apr 26];38(9):1626-34. Available from: http://www.ncbi.nlm.nih.gov/pubmed/16960524.

57. Deci EL, Ryan RM. Hedonia, Eudaimonia, and Well-Being: an Introduction. [cited 2018 Mar 1]; Available from: https://link.springer.com/content/pdf/10. 1007\%2Fs10902-006-9018-1.pdf

58. Bossmann T, Kanning M, Koudela-Hamila S, Hey S, Ebner-Priemer U. The Association between Short Periods of Everyday Life Activities and Affective States: A Replication Study Using Ambulatory Assessment. Front Psychol [Internet]. 2013 Apr 15 [cited 2018 Jun 19];4:102. Available from: http:// journal.frontiersin.org/article/10.3389/fpsyg.2013.00102/abstract

59. Lyubomirsky S, Lepper HS. A measure of subjective happiness: preliminary reliability and construct validation. Soc Indic Res. 1999;46(2):137-55.

60. Cummins RA, Eckersley R, Pallant J, van Vugt J, Misajon R. Developing a National Index of Subjective Wellbeing: The Australian Unity Wellbeing Index. Soc Indic Res [Internet]. 2003 [cited 2018 Jul 11];64(2):159-90. Available from: http://link.springer.com/10.1023/A:1024704320683

61. Sampson RJ, Raudenbush SW, Earls F. Neighborhoods and violent crime: a multilevel study of collective efficacy. Science [Internet]. 1997 Aug 15 [cited 2018 mar 15];277(5328):918-24. Available from: http://www.ncbi.nlm.nih. gov/pubmed/9252316.

62. Statistics Canada. Generalized social survey - social identity [Internet]. 2013 [cited 2018 Jun 26]. Available from: https://www.statcan.gc.ca/eng/ statistical-programs/instrument/5024_Q1_V3\#a35

63. Wang B, Gao L, Juan Z. A trip detection model for individual smartphonebased GPS records with a novel evaluation method. Adv Mech Eng [Internet]. 2017 Jun 6 [cited 2018 May 11];9(6):168781401770506. Available from: http://journals.sagepub.com/doi/10.1177/1687814017705066

64. Xiao G, Juan Z, Zhang C. Travel mode detection based on GPS track data and Bayesian networks. Comput Environ Urban Syst [Internet]. 2015 Nov 1 [cited 2018 May 11];54:14-22. Available from: https://www.sciencedirect. com/science/article/pii/S0198971515000587

65. Chen CS, Rinsurongkawong V, Eick CF, Twa MD. Change Analysis in Spatial Data by Combining Contouring Algorithms with Supervised Density Functions. In Springer, Berlin, Heidelberg; 2009 [cited 2018 May 14]. p. 90714. Available from: http://link.springer.com/10.1007/978-3-642-01307-2_95

66. Qiaoping Z, Couloigner I. Automatic road change detection and GIS updating from high spatial remotely-sensed imagery. Geo-spatial Inf Sci [Internet]. 2004 Jan [cited 2018 May 18];7(2):89-95. Available from: http:// www.tandfonline.com/doi/abs/10.1007/BF02826642

67. Boss D, Nelson T, Winters M. Monitoring city wide patterns of cycling safety. Accid Anal Prev [Internet]. 2018 Feb 1 [cited 2018 May 14];111:101-8. Available from: https://www.sciencedirect.com/science/article/pii/S0001457517303950?via\%3Dihub

68. Cousens S, Hargreaves J, Bonell C, Armstrong B, Thomas J, Kirkwood BR, et al. Alternatives to randomisation in the evaluation of public-health interventions: statistical analysis and causal inference. J Epidemiol Community Health [Internet]. 2011 Jul 1 [cited 2018 Apr 30];65(7):576-81. Available from: http://www.ncbi.nlm.nih.gov/pubmed/19666633.

69. Bonell CP, Hargreaves J, Cousens S, Ross D, Hayes R, Petticrew M, et al. Alternatives to randomisation in the evaluation of public health interventions: design challenges and solutions. J Epidemiol Community Health [Internet]. 2011 Jul 1 [cited 2018 Apr 26];65(7):582-7. Available from: http://www.ncbi.nlm.nih.gov/pubmed/19213758.

70. Oldenburg CE, Moscoe E, Bärnighausen T. Regression Discontinuity for Causal Effect Estimation in Epidemiology. Curr Epidemiol Reports [Internet].
2016 Sep 5 [cited 2018 May 18];3(3):233-41. Available from: http://link springer.com/10.1007/s40471-016-0080-x

71. Wing C, Simon K, Bello-Gomez RA. Designing Difference in Difference Studies: Best Practices for Public Health Policy Research. Annu Rev Public Health [Internet]. 2018 Apr 2 [cited 2018 Apr 30];39(1):453-69. Available from: http://www.annualreviews.org/doi/10.1146/annurev-publhealth040617-013507

72. Lopez Bernal J, Cummins S, Gasparrini A. Interrupted time series regression for the evaluation of public health interventions: a tutorial. Int J Epidemiol [Internet]. 2016 Jun 9 [cited 2018 May 18];46(1):dyw098. Available from: https://academic.oup.com/ije/article-lookup/doi/10.1093/ije/dyw098

73. Brodersen KH, Gallusser F, Koehler J, Remy N, Scott SL. Inferring causal impact using Bayesian structural time-series models [Internet]. 2015 [cited 2018 Jan 14]. Available from: https://research.google.com/pubs/pub41854. html

74. Mays N, Pope C. Rigour and qualitative research. BMJ [Internet]. 1995 Jul 8 [cited 2018 Jun 19];311(6997):109-12. Available from: http://www.ncbi.nlm. nih.gov/pubmed/7613363.

75. Cartier Y, Benmarhnia T, Brousselle A. Tool for assessing health and equity impacts of interventions modifying air quality in urban environments. Eval Program Plann [Internet]. 2015 Dec 1 [cited 2018 Jun 26];53:1-9. Available from: https://www.sciencedirect.com/science/article/pii/S0149718915000713

76. Haggis C, Sims-Gould J, Winters M, Gutteridge K, McKay HA. Sustained impact of community-based physical activity interventions: key elements for success. BMC Public Health [Internet]. 2013 Dec 27 [cited 2018 Apr 26];13(1): 892. Available from: http://www.ncbi.n/m.nih.gov/pubmed/24069938.

77. Dawson A, Sim J. The nature and ethics of natural experiments. J Med Ethics [Internet]. 2015 Oct [cited 2018 Apr 26];41(10):848-53. Available from: http://www.ncbi.n/m.nih.gov/pubmed/26187285.

78. Fuller D, Shareck M, Stanley K. Ethical implications of location and accelerometer measurement in health research studies with mobile sensing devices. Soc Sci Med [Internet]. 2017 Oct 1 [cited 2018 Apr 26];191:84-8. Available from: https://www.sciencedirect.com/science/article/pii/ S0277953617305245

79. Bader MDM, Mooney SJ, Rundle AG. Protecting Personally Identifiable Information When Using Online Geographic Tools for Public Health Research. Am J Public Health [Internet]. 2016 Feb [cited 2018 Apr 26];106(2): 206-8. Available from: http://www.ncbi.nlm.nih.gov/pubmed/26794375.

80. Hernán MA. The C-Word: Scientific Euphemisms Do Not Improve Causal Inference From Observational Data. Am J Public Health [Internet]. 2018 May 4 [cited 2018 May 14];108(5):616-9. Available from: http://ajph. aphapublications.org/doi/10.2105/AJPH.2018.304337

81. Panter J, Guell C, Prins R, Ogilvie D. Physical activity and the environment: conceptual review and framework for intervention research. Int J Behav Nutr Phys Act [Internet]. 2017 Dec 15 [cited 2018 May 18];14(1):156. Available from: https://ijbnpa.biomedcentral.com/articles/10.1186/s12966017-0610-z

82. Kwan M-P. The Uncertain Geographic Context Problem. Ann Assoc Am Geogr [Internet]. 2012 Sep [cited 2018 May 18];102(5):958-68. Available from: http://www.tandfonline.com/doi/abs/10.1080/00045608.2012.687349

\section{Ready to submit your research? Choose BMC and benefit from:}

- fast, convenient online submission

- thorough peer review by experienced researchers in your field

- rapid publication on acceptance

- support for research data, including large and complex data types

- gold Open Access which fosters wider collaboration and increased citations

- maximum visibility for your research: over $100 \mathrm{M}$ website views per year

At BMC, research is always in progress.

Learn more biomedcentral.com/submission 